\title{
Synthetic Biology Tools for the Fast-Growing Marine Bacterium Vibrio
}

\section{natriegens}

Tanya Tschirhart ${ }^{\dagger}$, Vrinda Shukla ${ }^{\ddagger}$, Erin E. Kelly§, Zachary Schultzhaus ${ }^{\S}$, Erin NewRingeisen ${ }^{\ddagger}$ Jeffrey Erickson", Zheng Wang*, Whitney Garcia ${ }^{\star}$, Emaleigh $\mathrm{Curl}^{\#}$, Robert G. Egbert ${ }^{\ddagger}$, Enoch Yeung^, Gary J. Vora**

\begin{abstract}
${ }^{\dagger}$ American Society for Engineering Education, Postdoctoral Fellowship Program, US Naval Research Laboratory, Washington, D.C. 20375, United States of America †enter for Bio/Molecular Science and Engineering, US Naval Research Laboratory, Washington, D.C. 20375, United States of America

$\S$ National Research Council, Postdoctoral Fellowship Program, US Naval Research Laboratory, Washington, D.C. 20375, United States of America

"Biological Sciences Division, Pacific Northwest National Laboratory, Richland, WA 99352, United States of America

${ }^{\&}$ Earth and Biological Sciences Directorate, Pacific Northwest National Laboratory, Richland, WA 99352, United States of America

\#Biomolecular Science and Engineering, University of California Santa Barbara, Santa Barbara CA 93106, United States of America

^Department of Mechanical Engineering, University of California Santa Barbara, Santa Barbara, CA 93106, United States of America
\end{abstract}

*Corresponding Author Gary J. Vora, Ph.D., Center for Bio/Molecular Science \& Engineering, US Naval Research Laboratory, Bldg. 30 / Code 6910, 4555 Overlook Avenue SW, Washington D.C. 20375, United States of America. Tel: 202.767.0394, Fax: 202.767.9594, E-mail: gary.vora@nrl.navy.mil 
Table S1 - V. natriegens doubling time ( $\mathrm{min}$ ) in various media with different plasmids (Figure 1)

\begin{tabular}{|l|c|c|c|l|l|l|l|}
\hline & \multicolumn{1}{|c|}{$\begin{array}{l}\text { Rich } \\
\text { media }\end{array}$} & \multicolumn{6}{|c|}{ Minimal media } \\
\hline & $\begin{array}{l}\text { LB }+ \\
\text { V2 salts }\end{array}$ & Glucose & Sucrose & $\begin{array}{l}\text { N-acetyl- } \\
\text { glucosamine }\end{array}$ & Mannitol & Arabinose & Glycerol \\
\hline WT & $11.7 \pm 0.4$ & $22.6 \pm 0.2$ & $22.1 \pm 0.2$ & $22.5 \pm 0.3$ & $29.5 \pm 0.7$ & $45.2 \pm 0.3$ & $51.9 \pm 8.7$ \\
\hline $\begin{array}{l}\text { Empty } \\
\text { vector }\end{array}$ & $11.9 \pm 1.5$ & $28.2 \pm 0.1$ & $26.8 \pm 1.2$ & $26.4 \pm 0.1$ & $37.4 \pm 0.5$ & $47.11 \pm 0.6$ & $53.6 \pm 3.2$ \\
\hline GFP & $12.2 \pm 1.9$ & $26.8 \pm 0.5$ & $27.6 \pm 0.2$ & $26.7 \pm 0.2$ & $38.0 \pm 0.6$ & $47.8 \pm 0.9$ & $52.2 \pm 4.1$ \\
\hline TYR & $12.4 \pm 2.0$ & $37.9 \pm 0.9$ & $32.8 \pm 1.8$ & $34.8 \pm 2.0$ & $37.3 \pm 4.3$ & $46.1 \pm 0.3$ & $65.6 \pm 9.3$ \\
\hline
\end{tabular}

Table S2 - Plasmids used for maintenance testing (Figure 2a)

\begin{tabular}{|l|l|l|}
\hline Plasmid & Resistance & Origin \\
\hline pDawn & Kan & pMB1 \\
\hline pBR322 & Ap & ColE1/pBR322 \\
\hline pSEVA181 & $\mathrm{Ap}$ & $\mathrm{pUC}$ \\
\hline pSEVA227R & $\mathrm{Km}$ & $\mathrm{RK} 2$ \\
\hline pSEVA237R & $\mathrm{Km}$ & $\mathrm{pBBR} 1$ \\
\hline pSEVA247Y & $\mathrm{Km}$ & $\mathrm{pRO} 1600 / \mathrm{ColE1}$ \\
\hline pSEVA261 & $\mathrm{Km}$ & $\mathrm{p} 15 \mathrm{~A}$ \\
\hline pVSV105 & $\mathrm{Cm}$ & $\mathrm{pES} 213$ \\
\hline
\end{tabular}

Table S3 - Plasmids and primers used for plasmid copy number testing (Figure 2b)

\begin{tabular}{|l|l|l|l|l|}
\hline $\begin{array}{c}\text { Plasmid } \\
\text { name }\end{array}$ & Resistance & \multicolumn{1}{|c|}{ Origin } & $\begin{array}{l}\text { Size } \\
(\mathbf{b p})\end{array}$ & \multicolumn{1}{|c|}{ qPCR primers } \\
\hline pSEVA181 & Ap & pUC & 2631 & $\begin{array}{l}\text { F: ATTGCGGATAAAAGCGGTGC } \\
\text { R: ACCACAATACGGCTCGGTTT }\end{array}$ \\
\hline pSEVA227R & Km & RK2 & 4516 & $\begin{array}{l}\text { F: GGGATTTTCTTGTTGCGCGT } \\
\text { R: CCTTGTTCGATATTGCGCCG }\end{array}$ \\
\hline pSEVA247Y & Km & $\begin{array}{l}\text { pRO1600/C } \\
\text { olE1 }\end{array}$ & 4272 & $\begin{array}{l}\text { F: CCATCGTCGCTATGTCCTCC } \\
\text { R: CAGGAACAGCGGATCGTTCT }\end{array}$ \\
\hline pSEVA237R & Km & pBBR1 & 3816 & $\begin{array}{l}\text { F:TGAAGGGCGAGATCAAGCAG } \\
\text { R: GGCTTCTTGGCCTTGTAGGT }\end{array}$ \\
\hline DVA & Ap & $\begin{array}{l}\text { Hybrid:Col } \\
\text { E1/pMB1/p } \\
\text { BR322/pUC }\end{array}$ & 2606 & $\begin{array}{l}\text { F: CCGCTTACCGGATACCTGTC } \\
\text { R: TTGGAGCGAACGACCTACAC }\end{array}$ \\
\hline pJV298 & Cm & p15A & 5120 & $\begin{array}{l}\text { F:TGTACTGCCTTCCAGAATTAAG } \\
\text { R: CTGGTCCACCTACAACAAAG }\end{array}$ \\
\hline pVSV105 & Cm & pES213 & 5780 & $\begin{array}{l}\text { F: CGGTCTGCAGGATGACCAAT } \\
\text { R: GTAACGCACTGAGAAGCCCT }\end{array}$ \\
\hline $\begin{array}{l}\text { Genomic } \\
\text { DnaE }\end{array}$ & - & - & - & $\begin{array}{l}\text { F: CGTCGTGCGATGGGTAAGAA } \\
\text { R: GTCGAAGATTTTCATCGCCA }\end{array}$ \\
\hline
\end{tabular}


Table S4 - Promoters used in Figure $4 \mathrm{~b}$ and values

\begin{tabular}{|l|l|l|l|l|}
\hline & \multicolumn{2}{|l|}{ DVK backbone } & \multicolumn{2}{l|}{ DVC backbone } \\
\hline Promoter & + RiboJ & - RiboJ & + RiboJ & - RiboJ \\
\hline J23102 & 605.09 & 3637.35 & 688.51 & 3018.97 \\
\hline J23106 & 287.30 & 848.87 & 362.51 & 918.97 \\
\hline SJM901 & 739.10 & 250.33 & 1427.54 & 8929.62 \\
\hline J23108 & 423.11 & 223.332 & 616.99 & 4807.73 \\
\hline
\end{tabular}

Table S5 - Promoters used in Figure $4 \mathrm{c}$ and values

\begin{tabular}{|l|l|l|l|l|}
\hline \multicolumn{3}{|l|}{ E. coli } & \multicolumn{2}{l|}{ V. natriegens } \\
\hline Promoter & GFP & mcherry & GFP & mcherry \\
\hline J23106 & 651.65 & 10.09 & 11.48 & 4.35 \\
\hline J23102 & 1330.02 & 13.35 & 22.57 & 8.98 \\
\hline SJM901 & 2564.84 & 22.21 & 63.06 & 13.99 \\
\hline J23108 & 890.55 & 10.35 & 2.60 & 5.95 \\
\hline None & 396.91 & 5.64 & 16.38 & 2.81 \\
\hline
\end{tabular}

Table S6 - Plasmids used in this work not already described

\begin{tabular}{|l|l|l|}
\hline Plasmid name & Information & Reference \\
\hline pDawn & $\begin{array}{l}\text { Vector with blue-light driven induction machinery, Kan, } \\
\text { ColE1 }\end{array}$ & $\begin{array}{l}\text { Ohlendorf } \text { et } \\
\text { al. }{ }^{l}\end{array}$ \\
\hline pDawn-mcherry & pDawn with blue-light driven mcherry expression & This work \\
\hline MK1274 & $\begin{array}{l}\text { Plasmid that expresses the Mixed Feedback Loop version of } \\
\text { the UBER system with a T7RNAP translation rate of 300 and } \\
\text { a TetR translation rate of 35149, pBR322, Amp }\end{array}$ & $\begin{array}{l}\text { Kushwaha } \text { et } \\
\text { al. }{ }^{2}\end{array}$ \\
\hline MK1283 & $\begin{array}{l}\text { Plasmid that expresses the Mixed Feedback Loop version of } \\
\text { the UBER system with a T7RNAP translation rate of 1535 } \\
\text { and a TetR translation rate of 30709, pBR322, Amp }\end{array}$ & $\begin{array}{l}\text { Kushwaha } \text { et } \\
\text { al. }\end{array}$ \\
\hline pJV-UBR-74 & $\begin{array}{l}\text { The pAK plasmid expresses GFP driven by a T7 promoter, } \\
\text { pBBR1, Kan }\end{array}$ & $\begin{array}{l}\text { Kushwaha } \text { et } \\
\text { al. }\end{array}$ \\
\hline pJV-UBR-83 & pJV298 with the MK1274 and MK969 TU's & This work \\
\hline pJV298 with the MK1283 and MK969 & This work \\
\hline pTSara-N748D & $\begin{array}{l}\text { Expresses both fragments of T7 RNAP split at position 179. } \\
\text { fragment has the point mutation N748D. Contains a } \\
\text { constitutive araC ORF, p15A, CmR }\end{array}$ & Shis et al. ${ }^{3}$ \\
\hline
\end{tabular}




\begin{tabular}{|c|c|c|}
\hline $\begin{array}{l}\text { pET:CCCT:GFP } \\
\text { and } \\
\text { pET:GACT:GFP }\end{array}$ & $\begin{array}{l}\text { A modified pET } 28 \text { driving expression of GFP, biobrick part } \\
\text { Bba_E0040. No LacO site downstream of PT7. T7 promoter } \\
\text { has base pairs 'CCCT' or 'GACT' between }-11 \text { and }-8 \text {. Hybrid } \\
\text { ori, Kan }\end{array}$ & Shis et al. \\
\hline $\begin{array}{l}\text { pET AraC :CCCT: } \\
\text { GFP and pET } \\
\text { AraC:GACT:GFP- }\end{array}$ & $\begin{array}{l}\text { Either the } \mathrm{pET}: \mathrm{CCCT} \text { :GFP or } \mathrm{pET} \text { :GACT:GFP with the } \\
\text { AraC protein cloned for constitutive expression }\end{array}$ & This work \\
\hline pTs1b-wt/N748D & $\begin{array}{l}\text { Expresses both fragments of T7 RNAP split at position } 179 \text {. } \\
\text { The N-terminal fragment is driven by PLac while the C- } \\
\text { terminal fragment is driven by PBAD, p15A, CmR }\end{array}$ & Shis et al. \\
\hline pCas9-CR4 & $\begin{array}{l}\text { Cas9 nuclease under control of pTet promoter with ssrA tag } \\
\text { and constitutive tetR, p15A, CmR }\end{array}$ & Reisch et al. ${ }^{4}$ \\
\hline pCR4-GFP & pCas9-CR4 with GFP instead of the Cas9 protein & This work \\
\hline pET200/D/LacZ & Commercial protein expression plasmid, hybrid ori, Kan & Invitrogen \\
\hline pA5D5GFP & $\begin{array}{l}\text { DVK_AE vector assembled with } \mathrm{J} 23102, \mathrm{~B} 0032 \mathrm{~m} \text {, GFP, and } \\
\text { B0015 terminator }\end{array}$ & This work \\
\hline pB1D5GFP & $\begin{array}{l}\text { DVK vector assembled with } \mathrm{J} 23106, \mathrm{~B} 0032 \mathrm{~m}, \mathrm{GFP} \text {, and } \\
\text { B0015 terminator }\end{array}$ & This work \\
\hline DVC AE & $\begin{array}{l}\text { MoClo destination vector with AE overhangs as in CIDAR } \\
\text { kit, blue/white screening, p } 15 \mathrm{~A}, \mathrm{CmR}\end{array}$ & This work \\
\hline DVC AF & $\begin{array}{l}\text { MoClo destination vector with AF overhangs as in CIDAR } \\
\text { kit, blue/white screening, p15A, CmR }\end{array}$ & This work \\
\hline pB1D5LacZ & $\begin{array}{l}\text { DVK_AE vector assembled with J23106, B0032m, LacZ, } \\
\text { B0015 terminator }\end{array}$ & This work \\
\hline pCP1D5GFP & $\begin{array}{l}\text { DVC vector with native } \mathrm{P} 1 \text { promoter, } \mathrm{B} 0032 \mathrm{~m}, \mathrm{GFP}, \mathrm{B} 0015 \\
\text { terminator }\end{array}$ & This work \\
\hline pLAFR2 & RK2 replicon $\left(m o b^{+} t r a^{+} \lambda \cos \right)$ bearing tet gene & Riboli et al. ${ }^{3}$ \\
\hline
\end{tabular}

Table S7 - Promoter sequences used in this work - inducible and constitutive

\begin{tabular}{|c|c|c|}
\hline Name & Sequence & Source \\
\hline ptac & ttgacaattaatcatcggctcgtataatg & $\begin{array}{l}\text { pJV298 } \\
\text { plasmid }^{5}\end{array}$ \\
\hline $\mathrm{pBAD}$ & $\begin{array}{l}\text { acattgattatttgcacggcgtcacactttgctatgccatagcatttttatccataagatta } \\
\text { gcggatcctacctgacgctttttatcgcaactctctactgtttctccataccgttttttgg } \\
\text { gctagc }\end{array}$ & CIDAR kit ${ }^{6}$ \\
\hline pTet & gttgacactctatcgttgatagagttattttaccactccetatcagtgatagagaa & $\begin{array}{l}\text { pCas9-CR4 } \\
\text { plasmid }\end{array}$ \\
\hline FixK2 & 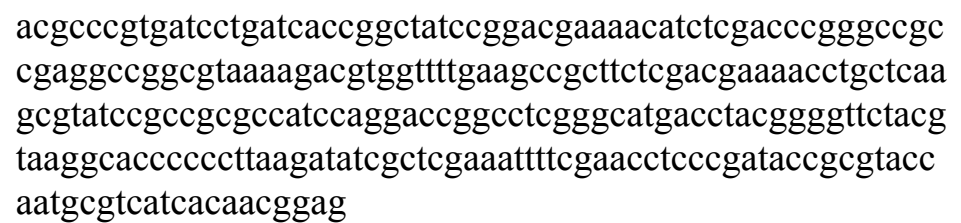 & $\begin{array}{l}\text { pDawn } \\
\text { plasmid }\end{array}$ \\
\hline
\end{tabular}




\begin{tabular}{|l|l|l|} 
J23108 & ctgacagctagctcagtcctaggtataatgctagc & This work \\
\hline J23103 & ctgatagctagctcagtcctagggattatgctagc & CIDAR kit \\
\hline SJM901 & tttacagctagctcagtcctaggtataatgctagc & This work \\
\hline J23116 & ttgacagctagctcagtcctagggactatgctagc & CIDAR kit \\
\hline J23114 & tttatggctagctcagtcctaggtacaatgctagc & This work \\
\hline J23107 & tttacggctagctcagccetaggtattatgctagc & CIDAR kit \\
\hline J23106 & tttacggctagctcagtcctaggtatagtgctagc & CIDAR kit \\
\hline SJM911 & ttgacagctagctcagtccttggtactgtgctagc & This work \\
\hline J23102 & ttgacagctagctcagtcctaggtactgtgctagc & CIDAR kit \\
\hline $\begin{array}{l}\text { V. natriegens } \\
\text { native P1 }\end{array}$ & $\begin{array}{l}\text { ttaggggtaaagttggataaataaggctttgagtgaaaagtcatcgtttaaccattatttt } \\
\text { tgcaaatttgcaaaataacgcttgccaacgtgagcgcgatctctataatgccacctcg } \\
\text { aagcgaaatagttaattgcctttacttttaaaaagtaaaataaaaagcaaaaagtgtttg } \\
\text { acacggaaaattatctcgctagaatggccgcctctcccgaa }\end{array}$ & $\begin{array}{l}\text { V. natriegens } \\
\text { genome }\end{array}$ \\
\hline
\end{tabular}

Table S8 - RBS sequences used in this work

\begin{tabular}{|l|l|l|}
\hline Name & Sequence & Source \\
\hline B0034m & agagaaagaggagaaatacta & $\begin{array}{l}\text { CIDAR } \\
\text { kit }\end{array}$ \\
\hline BCD2 & $\begin{array}{l}\text { gggcccaagttcacttaaaaaggagatc } \\
\text { aacaatgaaagcaatttcgtactgaaac } \\
\text { atcttaatcatgctaaggaggtttct }\end{array}$ & $\begin{array}{l}\text { CIDAR } \\
\text { kit }\end{array}$ \\
\hline BCD12 & $\begin{array}{l}\text { gggcccaagttcacttaaaaaggagatc } \\
\text { aacaatgaaagcaatttcgtactgaaac } \\
\text { atcttaatcatgctgcggagggtttct }\end{array}$ & $\begin{array}{l}\text { CIDAR } \\
\text { kit }\end{array}$ \\
\hline B0033m & agagtcacacaggactacta & $\begin{array}{l}\text { CIDAR } \\
\text { kit }\end{array}$ \\
\hline & $\begin{array}{l}\text { gggcccaagttcacttaaaaggagatc } \\
\text { aacaatgaaagcaatttcgtactgaaac } \\
\text { atcttaatcatgcatcggaccgtttct }\end{array}$ & $\begin{array}{l}\text { CIDAR } \\
\text { kit }\end{array}$ \\
\hline BCD8 & & $\begin{array}{l}\text { CIDAR } \\
\text { kit }\end{array}$ \\
\hline B0032m & agagtcacacaggaaagtacta & \\
\hline
\end{tabular}

Table S9 - Insulator part sequence used in this work

\begin{tabular}{|l|l|l|}
\hline Name & Sequence & Source \\
\hline $\begin{array}{l}\text { RiboJ } \\
\text { insulator }\end{array}$ & $\begin{array}{l}\text { AGCTGTCACCGGATGTGCTTTCCGGTCTGATGAGT } \\
\text { CCGTGAGGACGAAACAGCCTCTACAAATAATTTTG }\end{array}$ & $\begin{array}{l}\text { This work, sequence } \\
\text { from Lou } \text { et } a 1^{4}\end{array}$ \\
\hline
\end{tabular}

Table S10 - CDS sequences used in this work in Figure S5

\begin{tabular}{|l|l|l|}
\hline Name & Sequence & Source \\
\hline
\end{tabular}




\begin{tabular}{|c|c|c|}
\hline eBFP2 & 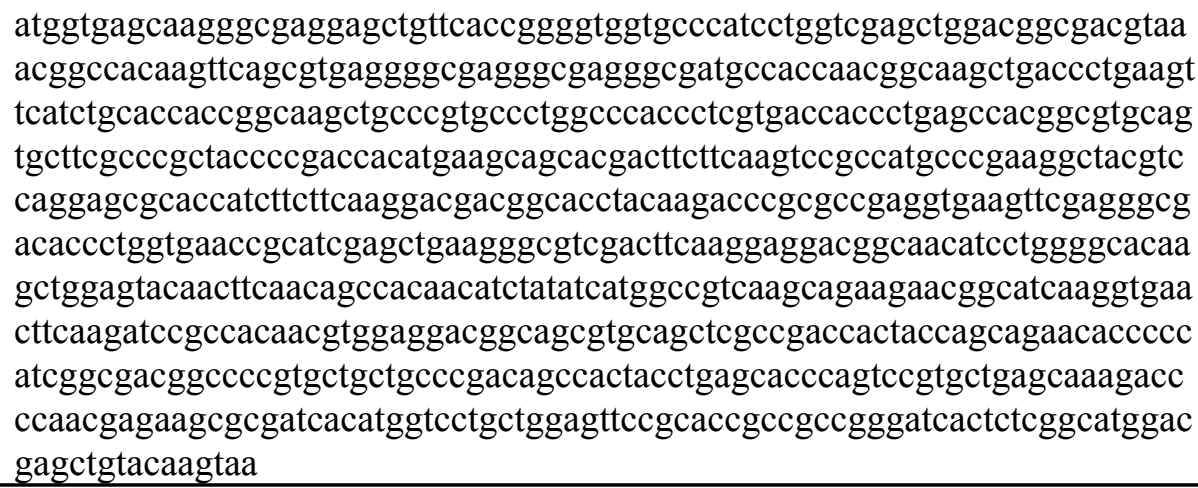 & CIDAR kit \\
\hline GFP & $\begin{array}{l}\text { atgcgtaaaggagaagaacttttcactggagttgtcccaattcttgttgaattagatggtgatgttaatgggcaca } \\
\text { aattttctgtcagtggagagggtgaaggtgatgcaacatacggaaaacttaccttaaatttattgcactactgg } \\
\text { aaaactacctgttccatggecaacacttgtcactactttcggttatggtgttcaatgctttgcgagatacccagat } \\
\text { catatgaaacagcatgactttttcaagagtgccatgeccgaaggttatgtacaggaaagaactatatttttcaaa } \\
\text { gatgacgggaactacaagacacgtgctgaagtcaagtttgaaggtgataccettgttaatagaatcgagttaaa } \\
\text { aggtattgattttaaagaagatggaaacattcttggacacaaattggaatacaactataactcacacaatgtatac } \\
\text { atcatggcagacaaacaaaagaatggaatcaaagttaacttcaaaattagacacaacattgaagatggaagc } \\
\text { gttcaactagcagaccattatcaacaaaatactccaattggcgatggccctgtccttttaccagacaaccattac } \\
\text { ctgtccacacaatctgccctttcgaaagatcccaacgaaaagagagatcacatggtccttcttgagtttgtaaca } \\
\text { gctgctgggattacacatggcatggatgaactatacaaataataa }\end{array}$ & CIDAR kit \\
\hline mCherry & 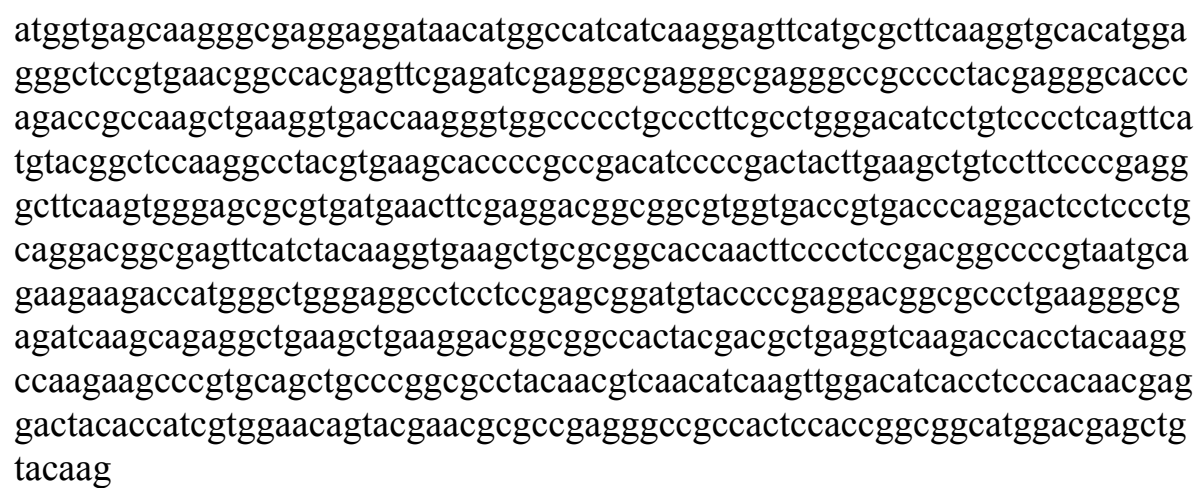 & $\begin{array}{l}\text { EcoFlex } \\
\text { kit }^{5}\end{array}$ \\
\hline sfgfp & $\begin{array}{l}\text { atgagcaaaggagaagaacttttcactggagttgtcccaattcttgttgaattagatggtgatgttaatgggcac } \\
\text { aaatttctgtccgtggagagggtgaaggtgatgctacaaacggaaaactcaccettaaatttatttgcactact } \\
\text { ggaaaactacetgttccgtggccaacacttgtcactactctgacctatggtgttcaatgcttttccgttatccgg } \\
\text { atcacatgaaacggcatgactttttcaagagtgccatgcccgaaggttatgtacaggaacgcactatatctttca } \\
\text { aagatgacgggacctacaagacgcgtgctgaagtcaagtttgaaggtgatacccttgttaatcgtatcgagtta } \\
\text { aagggtattgatttaaagaagatggaaacattcttggacacaaactcgagtacaactttaactcacacaatgta } \\
\text { tacatcacggcagacaaacaaaagaatggaatcaaagctaacttcaaaattcgccacaacgttgaagatggtt } \\
\text { ccgttcaactagcagaccattatcaacaaaatactccaattggcgatggccetgtccttttaccagacaaccatt } \\
\text { acctgtcgacacaatctgtcctttcgaaagatcccaacgaaaagcgtgaccacatggtccttcttgagtttgtaa } \\
\text { ctgctgctgggattacacatggcatggatgagctctacaaaactagt }\end{array}$ & $\begin{array}{l}\text { pTD103Lu } \\
\text { xI sfgfp -R }\end{array}$ \\
\hline
\end{tabular}




\begin{tabular}{|c|c|c|}
\hline $\begin{array}{l}\text { meSCFp } \\
3\end{array}$ & $\begin{array}{l}\text { atgagtaaaggagaagaacttttcactggagttgtcccaattcttgttgaattagatggtgatgttaatgggcaca } \\
\text { aatttctgtcagtggagagggtgaaggtgatgcaacatacggaaaacttacccttaaatttatttgcactactgg } \\
\text { aaaactacctgttccatggccaacacttgtcactactctcacttggggtgttcaatgcttgcaagatacccagat } \\
\text { catatgaaacagcatgactttttcaagagtgecatgccegaaggttatgtacaggaaagaactatatttttcaaa } \\
\text { gatgacgggaactacaagacacgtgctgaagtcaagttgaaggtgatacccttgttaatagaatcgagttaaa } \\
\text { aggtattgattttaaagaagatggaaacattcttggacacaaattggaatacaactacatctcagacaatgtata } \\
\text { catcacggcagacaaacaaaagaatggaatcaaagctaacttcaaaattagacacaacattgaagatggagg } \\
\text { cgttcaactagcagaccattatcaacaaaatactccaattggcgatggccctgtccttttaccagacaaccatta } \\
\text { cctgtccacacaatctaagctttcgaaagatcccaacgaaaagagagaccacatggtccttcttgagtttgtaa } \\
\text { cagctgctgggattacacatggcatggatgaactatacaaataa }\end{array}$ & $\begin{array}{l}\text { pRNA1- } \\
\text { mSCFP3 } \\
\text { from Johan } \\
\text { Paulsson } \\
\text { group, } \\
\text { Harvard }\end{array}$ \\
\hline RFP & $\begin{array}{l}\text { atggcttcctccgaggatgttatcaaagagttcatgcgtttcaaagttcgtatggaaggttccgttaacggtcac } \\
\text { gagttcgaaatcgaaggtgaaggtgaaggtcgtccgtacgaaggtacccagaccgctaaactgaaagttac } \\
\text { caaaggtggtccgetgecgttcgcttgggacatcctgtccccgcagttccagtacggttccaaagcttacgtta } \\
\text { aacacccggctgacatcccggactacctgaaactgtccttcccggaaggtttcaaatgggaacgtgttatgaa } \\
\text { cttcgaagatggtggtgttgttaccgttacccaggactcctcctgcaagacggtgagttcatctacaaagttaa } \\
\text { actgcgtggtaccaacttccegtccgacggtccggttatgcagaaaaaaaccatgggttgggaagettccac } \\
\text { cgaacgtatgtacccggaggatggtgctctgaaaggtgaaatcaaaatgcgtctgaaactgaaagacggtgg } \\
\text { tcactacgacgctgaagttaaaaccacctacatggctaaaaaaccggttcagctgccgggtgcttacaaaacc } \\
\text { gacatcaaactggacatcacctcccacaacgaggactacaccatcgttgaacagtacgaacgtgctgaaggt } \\
\text { cgtcactccaccggtgcttaataa }\end{array}$ & CIDAR kit \\
\hline LacZ & 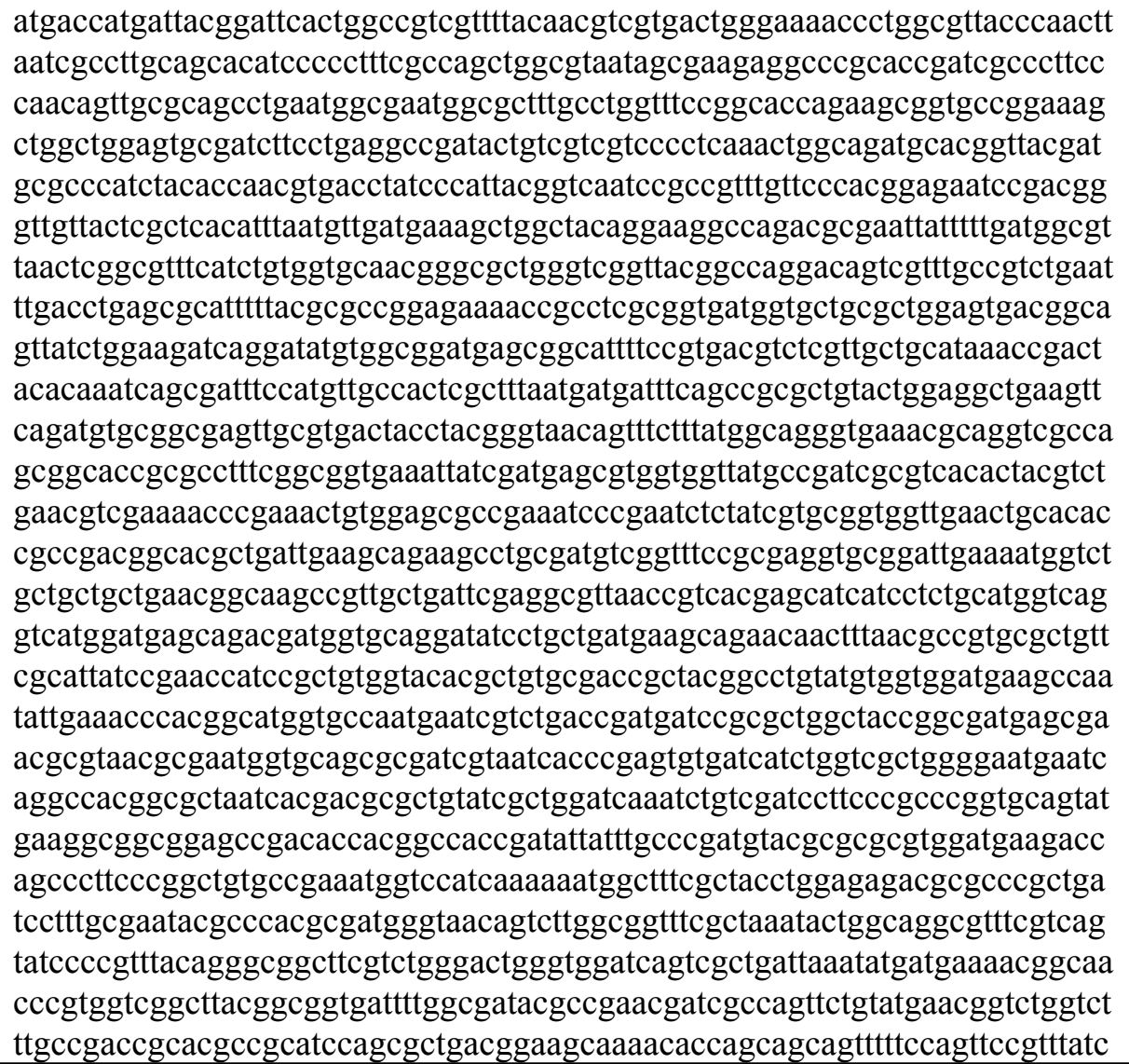 & $\begin{array}{l}\mathrm{pET} 200 / \mathrm{D} / \\
\mathrm{LacZ}\end{array}$ \\
\hline
\end{tabular}




\begin{tabular}{|c|c|c|}
\hline & 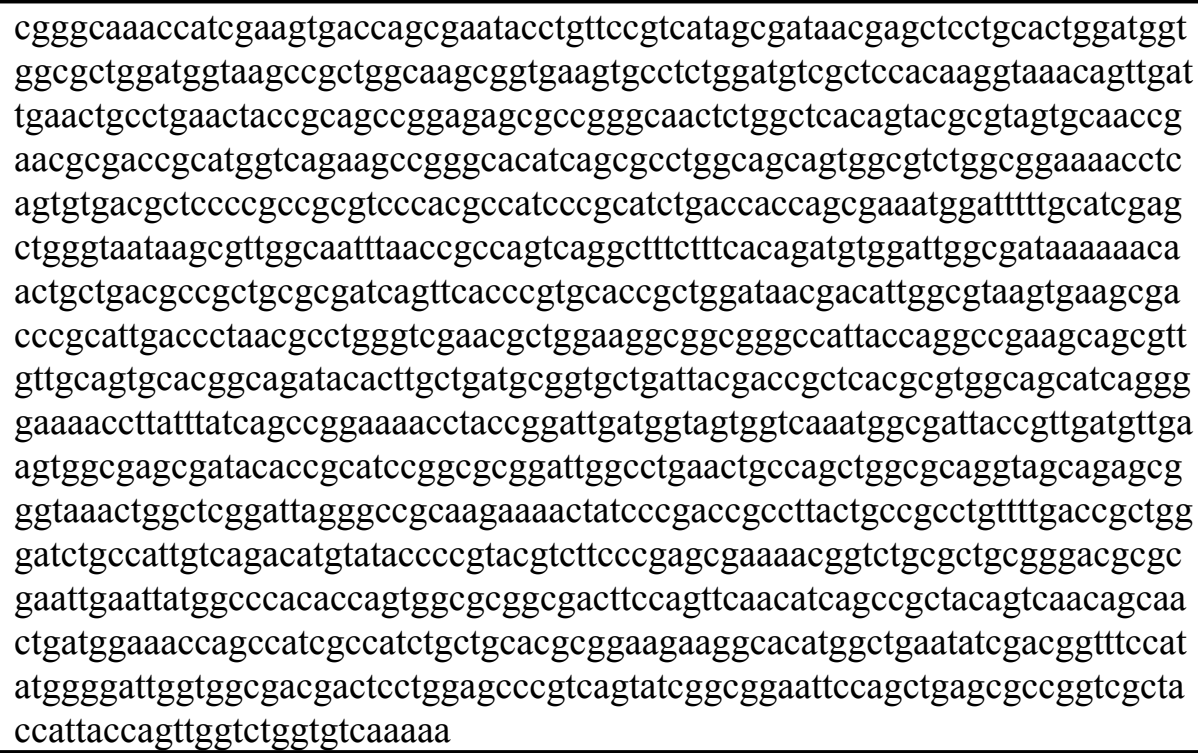 & \\
\hline YFP & 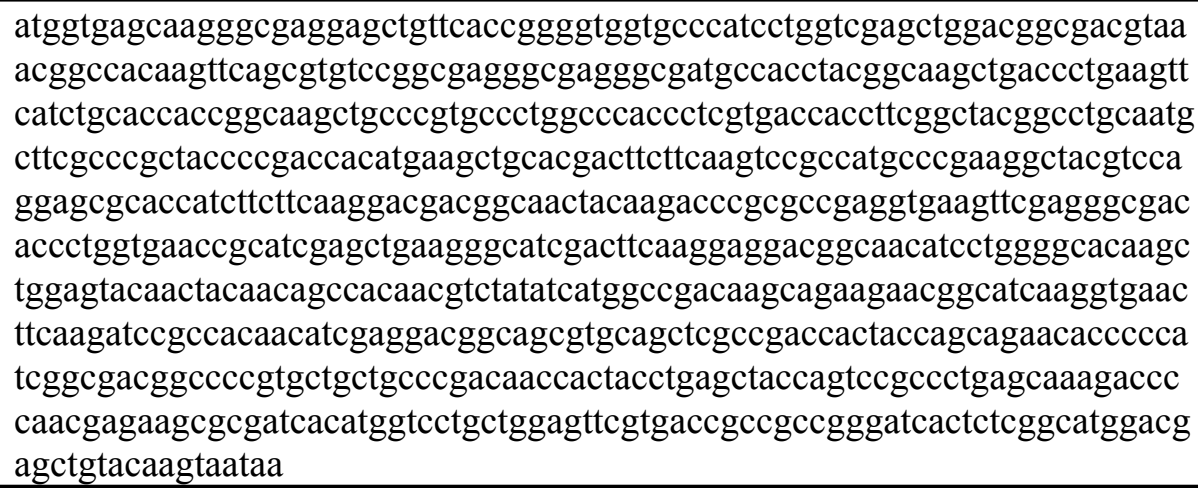 & CIDAR kit \\
\hline
\end{tabular}

Table S11 - Terminator sequences used in this work (Figure 5)

\begin{tabular}{|l|l|l|}
\hline Name & Sequence & Source \\
\hline Bba B0012 & tcacactggctcaccttcgggtgggcctttctgcgtttata & EcoFlex kit \\
\hline L3S1P51 & aaaaaaaaaaaaggctcccaaatcggggggccttttttattgataacaaaa & EcoFlex kit \\
\hline L1U1H08 & cccgcatgttcgcatgcgggtttttttt & EcoFlex kit \\
\hline L2U5H11 & tagcgtgcgaacagcacgctattgttgtat & EcoFlex kit \\
\hline Bba_B0015 & $\begin{array}{l}\text { ccaggcatcaaataaaacgaaaggctcagtcgaaagactgggcctttcgtttt } \\
\text { atctgttgtttgtcggtgaacgctctctactagagtcacactggctcaccttcgg } \\
\text { gtgggcctttctgcgtttata }\end{array}$ & CIDAR kit \\
\hline
\end{tabular}

Table S12 - Degradation tag sequences used in this work

\begin{tabular}{|l|l|l|}
\hline Name & Sequence & Source \\
\hline LAA & GCTGCTAACGACGAAAACTACGCTCTGGCTGCT & This work \\
\hline AAV & GCAGCAAACGACGAAAACTACGCTGCTGCTGTT & This work \\
\hline DAS & GCTGCTAACGACGAAAACTACGCTGACGCTTCT & This work \\
\hline
\end{tabular}

Table S13 - Plasmid assembly primers 


\begin{tabular}{|c|c|c|c|c|}
\hline Primer name & Sequence & Template & $\begin{array}{l}\text { Plasmid } \\
\text { construc } \\
\text { ted }\end{array}$ & Method \\
\hline pCas9-4GFP-F & GCTGCTAACGACGAAAACTAC & pCas9-CR4 & $\begin{array}{l}\text { pCR4- } \\
\text { GFP }\end{array}$ & GA \\
\hline pCas9-4GFP-R & AGATCCGAAGTCCTCTTTAGATC & pCas9-CR4 & & GA \\
\hline GFP-4pCas9-F & agaggacttcggatctATGCGTAAAGGAGAAGAAC & $\begin{array}{l}\text { GFP from } \\
\text { CIDAR }\end{array}$ & & GA \\
\hline GFP-4pCas9-R & $\begin{array}{l}\text { tttcgtcgttagcagcTTATTATTTGTATAGTTCATCCAT } \\
\text { G }\end{array}$ & $\begin{array}{l}\text { GFP from } \\
\text { CIDAR }\end{array}$ & & \\
\hline pJV-4DVC_R & GCGCAACGCAATTAATGTAAG & pJV298 & $\begin{array}{l}\text { DVC_A } \\
\text { F }\end{array}$ & GA \\
\hline pJV_4DVC_F & GATCCGGTGATTGATTGAG & pJV298 & & GA \\
\hline $\begin{array}{l}\text { LacZAF_DVCne } \\
\text { w-F }\end{array}$ & attaattgcgttgcgcTTCTAGAGACTAGTGGGTC & DVK_AF & & GA \\
\hline $\begin{array}{l}\text { LacZAF_DVCne } \\
\text { w-R }\end{array}$ & aatcaatcaccggatcCTACTAGTAGGTCTCTAGC & DVK_AF & & GA \\
\hline pJV-4DVCAE_F & $\begin{array}{l}\text { cattaattgcgttgcgcTGGAAGACATGGAGAGAGACCT } \\
\text { GC }\end{array}$ & pJV298 & $\begin{array}{l}\text { DVC_A } \\
\text { E }\end{array}$ & GA \\
\hline pJV-4DVCAE_R & caatcaatcaccggatcGGACTGCAGCGGCCGCTA & pJV298 & & GA \\
\hline LacZAE-F & GATCCGGTGATTGATTGAG & DVK_AE & & GA \\
\hline LacZAE-R & GCGCAACGCAATTAATGTAAG & DVK_AE & & GA \\
\hline mcherry-4pDn-F & $\begin{array}{l}\text { cggagctcgaattcggatccttaCTTGTACAGCTCGTCCATG } \\
\text { C }\end{array}$ & $\begin{array}{l}\text { mcherry from } \\
\text { EcoFlex }\end{array}$ & $\begin{array}{l}\text { pDawn- } \\
\text { mcherry }\end{array}$ & $\begin{array}{l}\text { Ligation w/ } \\
\text { pDAwn via } \\
\text { NdeI \& } \\
\text { BamHI }\end{array}$ \\
\hline mcherry-4pDn-R & gecgcgcggcagccatATGGTGAGCAAGGGCGAG & $\begin{array}{l}\text { mcherry from } \\
\text { EcoFlex }\end{array}$ & & $\begin{array}{l}\text { Ligation w/ } \\
\text { pDAwn via } \\
\text { NdeI \& } \\
\text { BamHI } \\
\end{array}$ \\
\hline $\begin{array}{l}\text { DVC- } \\
\text { UBERnew-F }\end{array}$ & GATCCGGTGATTGATTGAG & DVC_AE & $\begin{array}{l}\text { pJV- } \\
\text { UBR-74 } \\
\& \text { pJV- } \\
\text { UBR-83 }\end{array}$ & GA \\
\hline $\begin{array}{l}\text { DVC- } \\
\text { UBERnew_R }\end{array}$ & GCGCAACGCAATTAATGTAAG & DVC_AE & & GA \\
\hline 12xxnew_G-F & attaattgcgttgcgcGTTTTCCCAGTCACGACG & $\begin{array}{l}\text { Mk1274 \& } \\
\text { MK1283 }\end{array}$ & & GA \\
\hline 12xxnew-G-R & atggcgcaATCGATACAAAAAACCCCTAG & $\begin{array}{l}\text { Mk1274 \& } \\
\text { MK1283 }\end{array}$ & & GA \\
\hline 969new-UBER-F & tgtatcgatTGCGCCATCAGATCCTTG & MK969 & & GA \\
\hline $\begin{array}{l}\text { 969new-UBER- } \\
\mathrm{R}\end{array}$ & aatcaatcaccggatcCAGCAAAAAACCCCTCAAG & MK969 & & GA \\
\hline B1D5GFP-gib-F & AGGTCCAGGCATCAAATAAAAC & pB1D5GFP & $\begin{array}{l}\mathrm{pB} 1 \mathrm{D} 5 \mathrm{~L} \\
\mathrm{acZ}\end{array}$ & GA \\
\hline B1D5GFP-gib-R & CATTTAGTACTTTCCTGTGTG & pB1D5GFP & & GA \\
\hline LacZ-gib-F & acaggaaagtactaaatgATGACCATGATTACGGATTC & $\begin{array}{l}\mathrm{pET} 200 / \mathrm{D} / \mathrm{La} \\
\mathrm{cZ}\end{array}$ & & GA \\
\hline LacZ-gib-R & tttgatgcetggacctTTTTTGACACCAGACCAAC & $\begin{array}{l}\mathrm{pET} 200 / \mathrm{D} / \mathrm{La} \\
\mathrm{cZ}\end{array}$ & & GA \\
\hline
\end{tabular}




\begin{tabular}{|c|c|c|c|c|}
\hline P1-nboth-F & $\begin{array}{l}\text { tgcgttgcgetggaagacatTAGGGGTAAAGTTGGATAAA } \\
\text { TAAGGCTTTGAGT }\end{array}$ & $\begin{array}{l}V . \text { natriegens } \\
\text { genome }\end{array}$ & $\begin{array}{l}\mathrm{pCP} 1 \mathrm{D} 5 \\
\mathrm{GFP}\end{array}$ & GA \\
\hline P1-nR-R & tttcctgtgtgactctagtaTTCGGGAGAGGCGGCCA & $\begin{array}{l}V . \text { natriegens } \\
\text { genome }\end{array}$ & & GA \\
\hline pC-GFP-R & ATGTCTTCCAGCGCAACG & pCB1D5GFP & & GA \\
\hline pCD5-GFP-F & TACTagagtcacacaggaaagtactaAATG & pCB1D5GFP & & GA \\
\hline pET-4AraC-F & TAGCTCACTCATTAGGCAC & $\begin{array}{l}\text { pET:CCCT } \\
\text { or GACT: } \\
\text { GFP }\end{array}$ & $\begin{array}{l}\text { pET } \\
\text { AraC } \\
: \text { CCCT } \\
\text { or } \\
\text { GACT: } \\
\text { GFP } \\
\end{array}$ & GA \\
\hline pET-4AraC-R & ACTTACATTAATTGCGTTGC & $\begin{array}{l}\text { pET:CCCT } \\
\text { or GACT: } \\
\text { GFP }\end{array}$ & & GA \\
\hline AraC-4pET-F & $\begin{array}{l}\text { caacgcaattaatgtaagtTTATATACTAGAGAGAGAATA } \\
\text { TAAAAAGC }\end{array}$ & $\begin{array}{l}\text { pTSara- } \\
\text { N748D }\end{array}$ & & GA \\
\hline AraC-4pET-R & gcctaatgagtgagctaTTATGACAACTTGACGGC & $\begin{array}{l}\text { pTSara- } \\
\text { N748D }\end{array}$ & & GA \\
\hline
\end{tabular}

$\mathrm{GA}=$ Gibson Assembly. Uppercase primer portions bind to backbone.

Table S14 - Primers used for promoter part creation in CIDAR MoClo vector DVA_AB

\begin{tabular}{|l|l|l|l|l|}
\hline $\begin{array}{l}\text { Primer } \\
\text { name }\end{array}$ & Sequence & Template & $\begin{array}{l}\text { Part } \\
\text { constructed }\end{array}$ & Method \\
\hline $\begin{array}{l}\text { J23108- } \\
\text { F }\end{array}$ & cctaggtataatgctagcTACTAGAGACCTACTAGTAGCGGC & DVA-AB & $\begin{array}{l}\text { J23108 } \\
\text { promoter }\end{array}$ & $\begin{array}{l}\text { in vivo } \\
\text { cloning }\end{array}$ \\
\hline $\begin{array}{l}\text { J23108- } \\
\text { R }\end{array}$ & actgagctagctgtcagCTCCTGAGACCCACTAGTCTCTAG & DVA-AB & & \\
\hline J23114- & ctcagtcctaggtacaatgctagcTACTAGAGACCTACTAGTAGCGGC & DVA-AB & $\begin{array}{l}\text { J23114 } \\
\text { promoter }\end{array}$ & $\begin{array}{l}\text { in vivo } \\
\text { cloning }\end{array}$ \\
\hline $\begin{array}{l}\text { J23114- } \\
\text { R }\end{array}$ & cctaggactgagctagccataaCTCCTGAGACCCACTAGTCTCTAG & DVA-AB & & \\
\hline $\begin{array}{l}\text { SJM901- } \\
\text { DVA-2- } \\
\text { F }\end{array}$ & ctcagtcctaggtataatgctagcTACTAGAGACCTACTAGTAGCGGC & DVA-AB & $\begin{array}{l}\text { SJM901 } \\
\text { promoter }\end{array}$ & $\begin{array}{l}\text { in vivo } \\
\text { cloning }\end{array}$ \\
\hline $\begin{array}{l}\text { SJM901- } \\
\text { DVA-2- } \\
\text { R }\end{array}$ & cctaggactgagctagctgtaaCTCCTGAGACCCACTAGTCTCTAGAA & DVA-AB & & \\
\hline $\begin{array}{l}\text { SJM911- } \\
\text { F }\end{array}$ & gctcagtccttggtactgtgctagcTACTAGAGACCTACTAGTAGCGGC & DVA-AB & $\begin{array}{l}\text { SJM911 } \\
\text { promoter }\end{array}$ & $\begin{array}{l}\text { in vivo } \\
\text { cloning }\end{array}$ \\
\hline $\begin{array}{l}\text { SJM911- } \\
\text { R }\end{array}$ & taccaaggactgagctagctgtcaaCTCCTGAGACCCACTAGTCTCTAG & DVA-AB & & \\
\hline
\end{tabular}

Uppercase portion of primers binds to backbone.

Table S15 - Primers used for RiboJ part creation in CIDAR MoClo Vector B0032_BC

\begin{tabular}{|l|l|l|l|l|}
\hline Primer name & Sequence & Template & $\begin{array}{l}\text { Part } \\
\text { constructed }\end{array}$ & Method \\
\hline $\begin{array}{l}\text { RiboJ-RBS- } \\
\text { add-F }\end{array}$ & $\begin{array}{l}\text { agtccgtgaggacgaaacagctctacaaataatttgtttaatcTA } \\
\text { GAGAGAGTCACACAGGAAAGTAC }\end{array}$ & B0032m_BC & RiboJ & $\begin{array}{l}\text { In vivo } \\
\text { cloning }\end{array}$ \\
\hline
\end{tabular}


RiboJ-RBSadd-R gtttcgtcctcacggactcatcagaccggaaagcacatccggtgac agcTAGTATGAGACCCACTAGTC

Uppercase portion of primers binds to backbone.

Table S16 - Primers used to add protein degradation tags to GFP

\begin{tabular}{|l|l|l|l|l|}
\hline Primer name & Sequence & Template & Part constructed & Method \\
\hline DAS-GFP-F & $\begin{array}{l}\text { actacgctgacgcttctTAATAAAGGTCCA } \\
\text { GGCATC }\end{array}$ & pA5D5GFP & $\begin{array}{l}\text { DAS ssRA tag for } \\
\text { GFP }\end{array}$ & $\begin{array}{l}\text { in vivo } \\
\text { cloning }\end{array}$ \\
\hline DAS-GFP-R & $\begin{array}{l}\text { tttcgtcgttagcagcTTTGTATAGTTCAT } \\
\text { CCATGCC }\end{array}$ & pA5D5GFP & & \\
\hline pJV-DAS-add-F & $\begin{array}{l}\text { actacgctgacgcttctTGAGGATCCGGTG } \\
\text { ATTGATTG }\end{array}$ & pJV298 & $\begin{array}{l}\text { DAS ssRA tag for } \\
\text { GFP }\end{array}$ & $\begin{array}{l}\text { PCR and } \\
\text { ligation }\end{array}$ \\
\hline pJV-DAS-add-R & $\begin{array}{l}\text { tttcgtcgttagcagcGTTGTACAGTTCAT } \\
\text { CCATGCC }\end{array}$ & pJV298 & & \\
\hline LAA-GFP-add-F & $\begin{array}{l}\text { acgaaaactacgctctggctgctTAATAAAGG } \\
\text { TCCAGGCATC }\end{array}$ & pA5D5GFP & $\begin{array}{l}\text { LAA ssRA for } \\
\text { GFP }\end{array}$ & $\begin{array}{l}\text { in vivo } \\
\text { cloning }\end{array}$ \\
\hline LAA-GFP-add-R & $\begin{array}{l}\text { cgtagtttcgtcgttagcagcTTTGTATAGTT } \\
\text { CATCCATGCC }\end{array}$ & pA5D5GFP & & \\
\hline AAV-GFP-add-F & acgaaactacgctgctgctgttTAATAAAGG & pCAGGCATC & $\begin{array}{l}\text { AAV ssRA tag } \\
\text { for GFP }\end{array}$ & $\begin{array}{l}\text { in vivo } \\
\text { cloning }\end{array}$ \\
\hline AAV-GFP-add-R & $\begin{array}{l}\text { cgtagtttcgtcgttgctgcTTTGTATAGTT } \\
\text { CATCCATGCC }\end{array}$ & pA5D5GFP & & \\
\hline
\end{tabular}

Uppercase portion of primers binds to backbone.

Table S17 - Primers used to add CDS parts into CIDAR MoClo vector DVA_CD

\begin{tabular}{|l|l|l|l|l|}
\hline Primer name & Sequence & Template & $\begin{array}{l}\text { Part } \\
\text { constructed }\end{array}$ & Method \\
\hline DVA-CD-gib-F & AGGTAGAGACCTACTAGTAGC & DVA-CD & $\begin{array}{l}\text { DVA for } \\
\text { CDS parts }\end{array}$ & GA \\
\hline DVA-CD-gib-R & CATTTGAGACCCACTAGTC & DVA-CD & & \\
\hline & $\begin{array}{l}\text { ctagtgggtctcaaatgATGGTGAGCAAGG } \\
\text { mCh-gib-DVA-F }\end{array}$ & $\begin{array}{l}\text { pBP-mCherry } \\
\text { - EcoFlex }\end{array}$ & $\begin{array}{l}\text { meherry } \\
\text { DVA_CD } \\
\text { part }\end{array}$ & GA \\
\hline mCh-gib-DVA-R & $\begin{array}{l}\text { tactagtaggtctctacctTTACTTGTACAGC } \\
\text { TCGTCCATG }\end{array}$ & $\begin{array}{l}\text { pBP-mCherry } \\
\text { - EcoFlex }\end{array}$ & & \\
\hline & $\begin{array}{l}\text { pRNA1- } \\
\text { ven-SCFP3-gib-F }\end{array}$ & $\begin{array}{l}\text { mSCFP3 } \\
\text { DVA_CD } \\
\text { part }\end{array}$ & GA \\
\hline ven-SCFP3-gib-R & tactagtaggtctctacctTTATTTGTATAGT & $\begin{array}{l}\text { pRNA1- } \\
\text { mSCFP3 }\end{array}$ & & \\
\hline
\end{tabular}

$\mathrm{GA}=$ Gibson Assembly. Uppercase portion of primers binds to backbone. 
Table S18 - Primers used to assemble TU's with different terminators from EcoFlex kit into DVK_AE from CIDAR MoClo kit

\begin{tabular}{|l|l|l|l|l|}
\hline Primer name & Sequence & Template & Plasmid constructed & Method \\
\hline & $\begin{array}{l}\text { GCTTATGTCTTCTACT } \\
\text { DVK-gib-F }\end{array}$ & DVK-AE & $\begin{array}{l}\text { DVK with TU from } \\
\text { EcoFlex kit }\end{array}$ & GA \\
\hline DVK-gib-R & $\begin{array}{l}\text { CTCCATGTCTTCCACT } \\
\text { AG }\end{array}$ & DVK-AE & & \\
\hline & $\begin{array}{l}\text { agtggagacatggagCGTCT } \\
\text { CAATCTCTATTTTACA }\end{array}$ & $\begin{array}{l}\text { pTU1A constructs } \\
\text { (EcoFlex Kit) }\end{array}$ & & \\
Ecflx-term-gib-F & G & & GA \\
\hline & $\begin{array}{l}\text { tactagtagaagacataagcCGT } \\
\text { CTCTGGCAAACATATA }\end{array}$ & $\begin{array}{l}\text { pTU1A constructs } \\
\text { (EcoFlex Kit) }\end{array}$ & & \\
Ecflx-term-gib-R & AAC & & \\
\hline
\end{tabular}

$\mathrm{GA}=$ Gibson Assembly. Uppercase portion of primers binds to backbone. 


\section{Supplementary Figures}
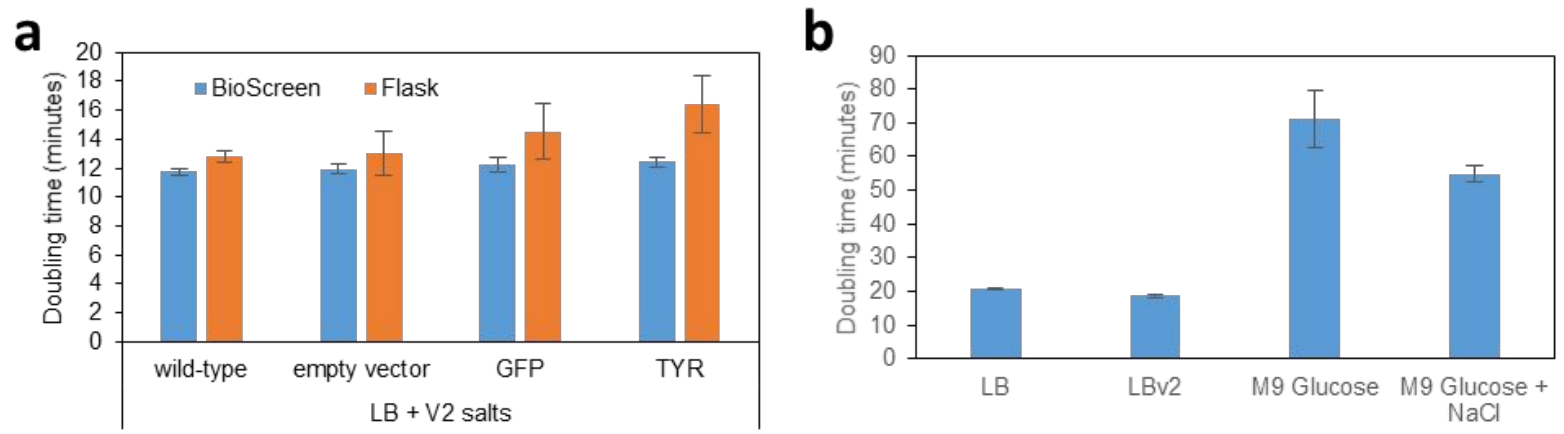

Figure S1. (a) Doubling time of $V$. natriegens with the indicated plasmid (or WT without plasmid) on $\mathrm{LB}+\mathrm{V} 2$ salts media in either the BioScreen machine or in shake-flasks at $37{ }^{\circ} \mathrm{C}$. Error bars represent standard deviation of biological triplicates. (b) Doubling time calculations for WT cells grown at $30^{\circ} \mathrm{C}$. Error bars represent standard deviation of biological triplicates. 

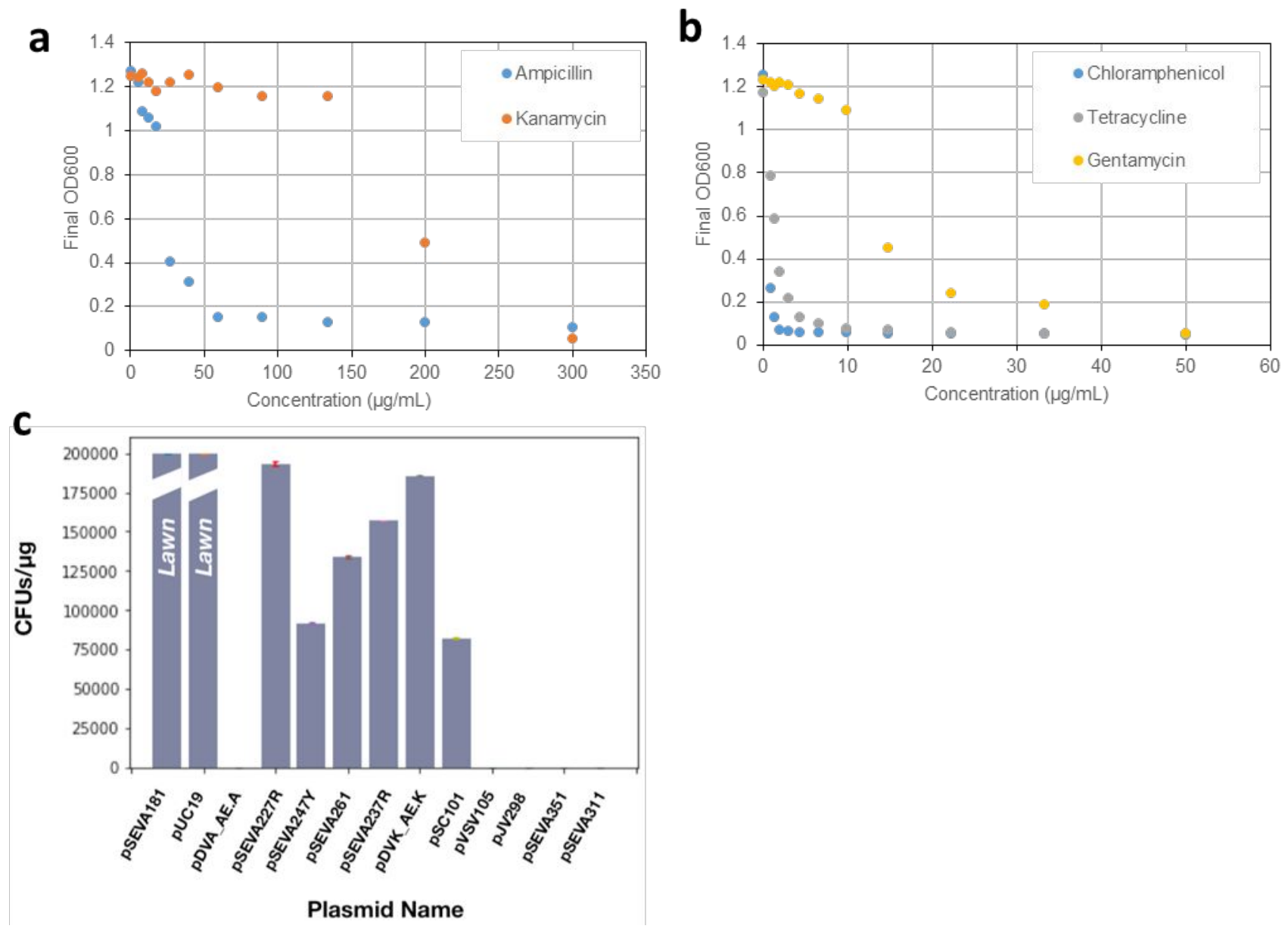

Figure S2. (a) \& (b) Final $\mathrm{OD}_{600}$ reading after overnight growth of $V$. natriegens $\mathrm{WT}$ in LBv2 with the indicated antibiotic concentrations at $37^{\circ} \mathrm{C}$. (c) Chemical transformation efficiency of a panel of plasmids in chemically competent cells, prepared using 1M sorbitol and Vmax Express Media. 

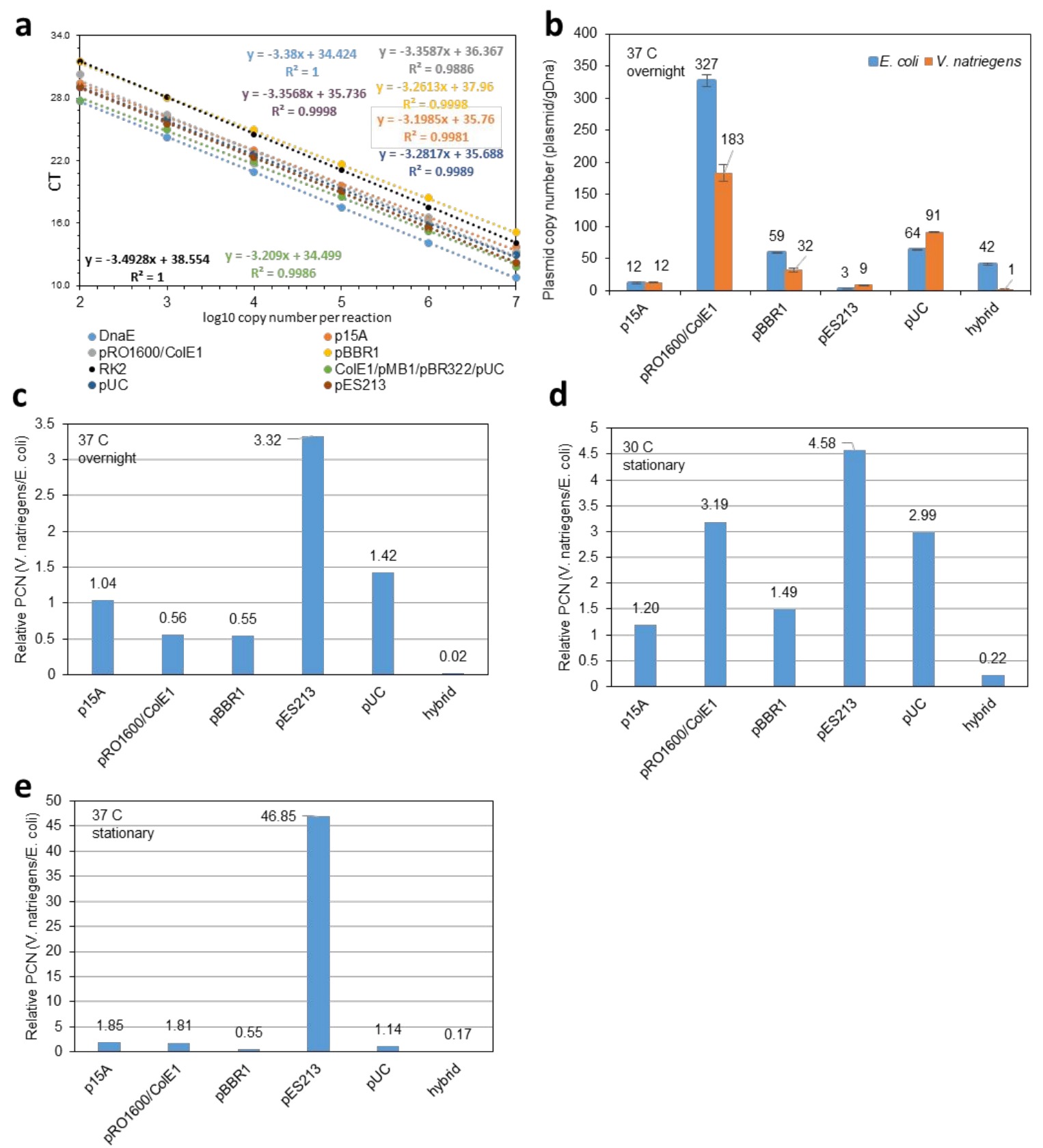

Figure S3. (a) Standard curves used for calculating absolute copy numbers of plasmid and gDNA targets from $V$. natriegens and E. coli cultures. Equations from linear regression determinations are presented for each qPCR target, and these were used to determine plasmid copy numbers in cell lysates. (b) Plasmid copy number in E. coli and $V$. natriegens of the plasmids with the listed origins of replication. Cells collected at stationary phase after growth at $37^{\circ} \mathrm{C}$ overnight. (c) Relative plasmid copy numbers $(V$. natriegens / E. coli) from the data in (b). (d) Relative plasmid copy numbers ( $V$. natriegens / E. coli) from the data in Figure 2b. (e) Relative plasmid copy numbers ( $V$. natriegens / E. coli) from the data in Figure 2c. Hybrid origin is ColE1/pMB1/pBR322/pUC. In (b), samples were run in technical triplicates and error bars represent standard deviation. For the plasmids and primers used in this figure see Tables S2 and S3. 

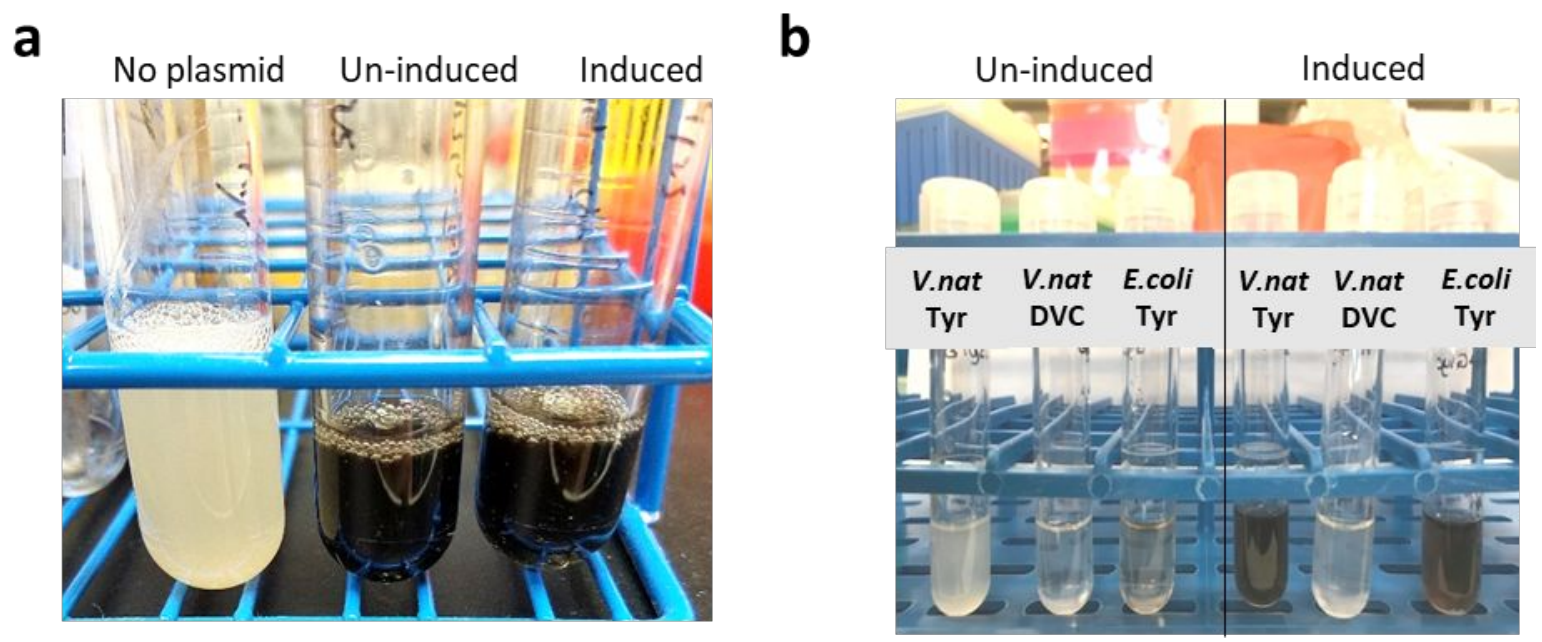

Figure S4. Tyrosinase induction (a) Photograph of $V$. natriegens after overnight culture in tyrosinase production media and components to promote tyrosinase activity and melanin production, seen here as a black pigment in the media (see Supplemental Methods). Cells were grown either without the production plasmid (No plasmid), with the plasmid but no IPTG (Uninduced) or with the plasmid and IPTG (Induced). (b) Photographs of $V$. natriegens and E. coli with arabinose-inducible tyrosinase construct. Cells were grown in tyrosinase production media with glycerol as the carbon source. Tyr indicates plasmid with the tyrosinase gene. DVC was used as a control plasmid. 


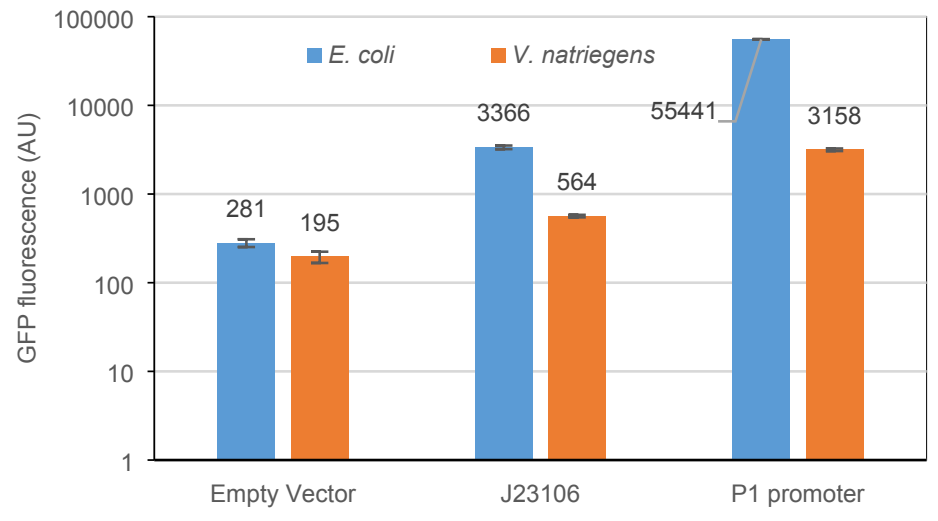

Figure S5. $V$. natriegens native $\mathrm{P} 1$ promoter. $E$. coli and $V$. natriegens GFP fluorescence as measured by flow cytometry with either the empty DVC vector, the DVC vector with J23106 promoter, B0032m RBS, GFP, and B0015 terminator, or with the P1 promoter with the same vector, RBS, GFP and terminator. 


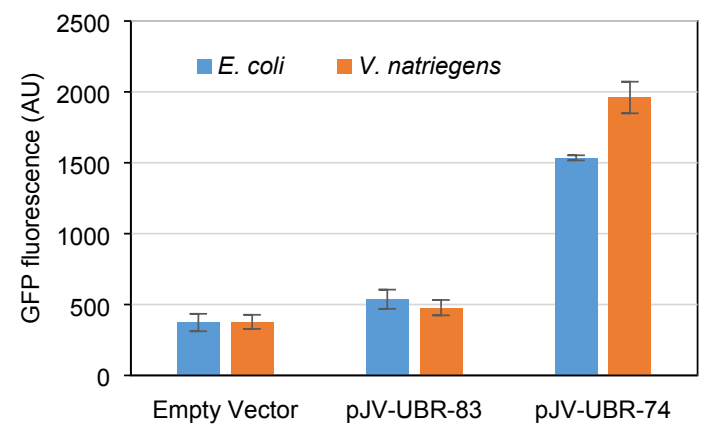

Figure S6. UBER system in $V$. natriegens - GFP fluorescence of E. coli and $V$. natriegens with the single constructed UBER plasmid. Either the MK1274 or MK1283 transcription unit was used in pJV-UBR-74 or pJV-UBR-83, respectively. Fluorescence was normalized by cell density $\left(\mathrm{OD}_{600}\right)$. 


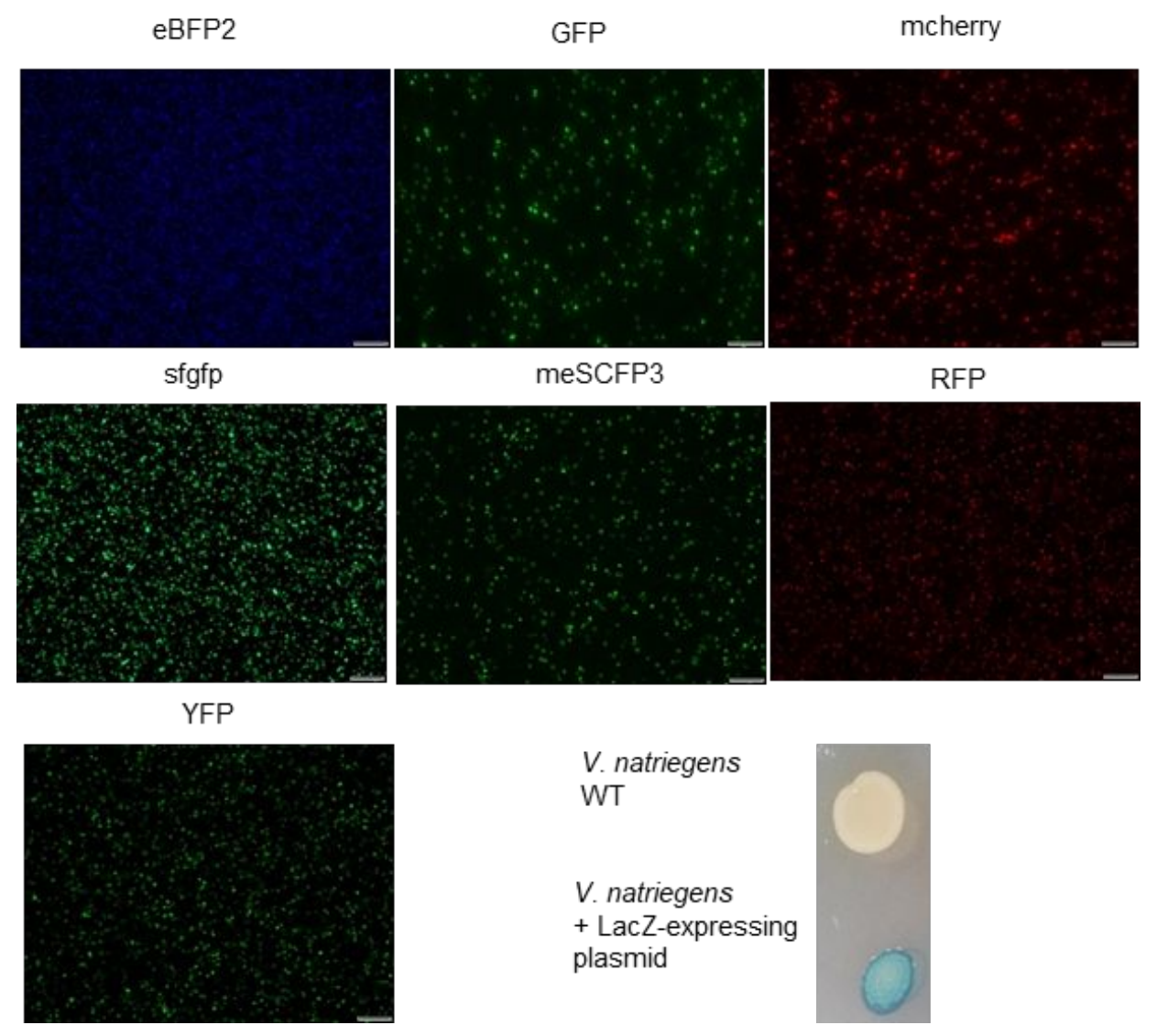

Figure S7. Microscopy images of $V$. natriegens expressing the indicated fluorescent proteins. Images were obtained using the $60 \mathrm{X}$ objective. Image showing $V$. natriegens on an agar plate containing X-gal (lower right). DVK backbone with J23102 promoter, B0032m RBS, indicated CDS, and B0015 terminator. All assembled from CIDAR Moclo Kit. MCherry, sfgfp, LacZ, and meSCFP were first cloned into DVA_CD to form CDS parts. 

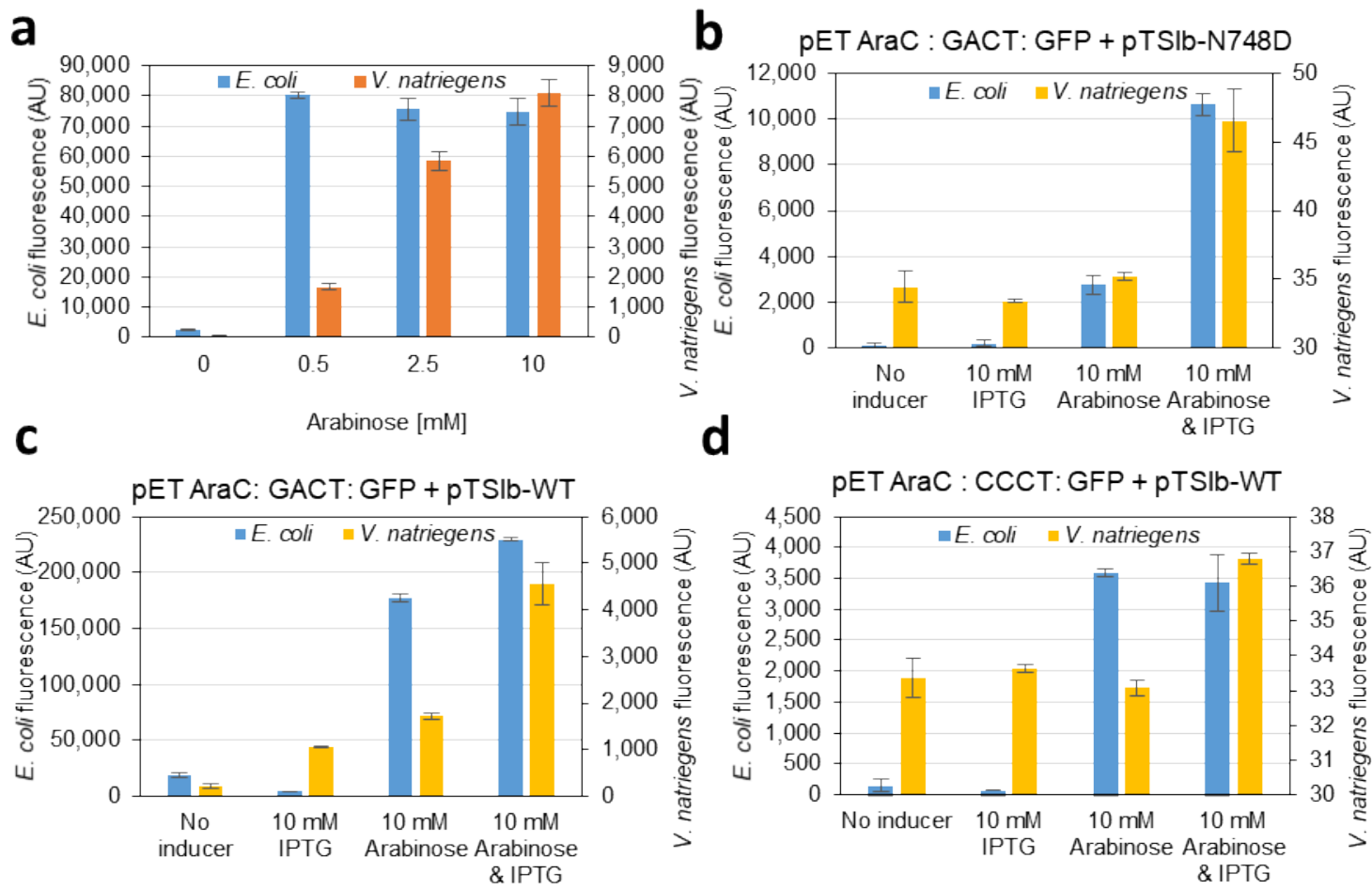

Figure S8. AND gate function. (a) T7-driven GFP fluorescence in E. coli and $V$. natriegens with the arabinose-induced split-T7-polymerase system (plasmids pTSara-N748D and pET:CCCT:GFP) after induction with the indicated concentrations of arabinose. (b-d)

Fluorescence of $E$. coli and $V$. natriegens transformed with the two indicated AND-gate plasmids after the indicated treatments. Fluorescence was measured with flow cytometry and the means of triplicates are shown. Error bars indicate standard deviation. 
List of specific constructs, as assembled, shown in each figure, where not already indicated:

Figure 3. (a) pJV298, (b) DVA assembled with TU1: J23102 promoter, B0032m RBS, AraC CDS, B0015 Terminator \& TU2: pBAD promoter, B0032 RBS, GFPm, B0015 Terminator. All from CIDAR MoClo kit. (c) pCR4-GFP. (d) pDawn-mcherry

Figure 4. (a) All promoters are in the DVK backbone (CIDAR MoClo kit) with the B0032m RBS, indicated promoter, GFP CDS, and B0015 Terminator. (b \& c) DVK or DVC were used as backbones, the indicated promoter, +/- RiboJ insulator with B0032m RBS (as one MoClo part), mcherry or GFP as CDS, B0015 Terminator. (d) All are in DVK backbone, J23106 promoter, indicated RBS, GFP, and B0015 Terminator assembled from the CIDAR MoClo kit.

Figure 5. (a) The indicated terminators were first assembled into the pTU1-A-LacZ plasmid with the SJM901 promoter, pET-RBS, mcherry, and indicated terminator from the EcoFlex MoClo kit. The whole transcriptional unit was moved into DVK to replace the LacZ fragment. See Table $\mathrm{S}$ for primers. (b) The DAS tag was added through PCR onto the end of GFP in the pJV298 plasmid. (c) The indicated tags were added onto the end of GFP through PCR onto the following plasmid: DVK (from CIDAR kit) with J23102 promoter, B0032m RBS, GFP, and B0015 terminator.

\section{SUPPLEMENTAL METHODS}

Antibiotic sensitivity testing. $V$. natriegens WT was grown overnight at $37^{\circ} \mathrm{C}$ in $\mathrm{LB}+$ $\mathrm{V} 2$ salts. In the morning, the cells were re-innoculated at $2 \%$ in LB+V2 salts with the indicated antibiotics, and a serial dilution (1.5X) in a 96-well plate was performed. The $200 \mu \mathrm{L}$ of cells in media + antibiotic were grown over the day in a plate reader with a BreathEasy film, after which the final $\mathrm{OD}_{600}$ was measured with the film off.

Part assembly using MoClo. For MoClo assembly using parts from the CIDAR kit (or those added into the kit with the same overhangs) the following protocol was used, as per Iverson et al: A volume calculated to be $40 \mathrm{fmol}$ of each DNA part and appropriate destination vector (MoClo DNA parts in CIDAR destination vectors or PCR products), 10-20 units of BsaI (Level 1) or 20 units BbsI (Level 2), 20 units of HC T4 DNA ligase, 1X T4 DNA ligase buffer, and nuclease free water at a total reaction volume of $20 \mu \mathrm{L}$ were added to a $0.6 \mathrm{~mL}$ PCR tube. Reactions were incubated with the following parameters: $37^{\circ} \mathrm{C}$ for 60 minutes, followed by 55 ${ }^{\circ} \mathrm{C}$ for 5 min and were then held at $4{ }^{\circ} \mathrm{C}$ or $-20^{\circ} \mathrm{C}$ until transformation.

For MoClo assembly using parts from the EcoFlex kit (or those added into the kit with the same overhangs) the following protocol was used, as per Moore et al: Approximately $100 \mathrm{ng}$ of each DNA part was combined with $50 \mathrm{ng}$ of destination vector, 10-20 units of BsaI, 20 units of HC T4 DNA ligase, 1X T4 DNA ligase buffer, and nuclease free water in a total reaction volume of $20 \mu \mathrm{L}$ in a $0.6 \mathrm{~mL}$ PCR tube. Reactions were incubated with the following parameters: 30 cycles of 5 minutes at $37^{\circ} \mathrm{C}$ and 10 minutes at $16^{\circ} \mathrm{C}$, followed by 5 minutes at $50{ }^{\circ} \mathrm{C}$ and 5 minutes at $80^{\circ} \mathrm{C}$. Reactions were held at $4{ }^{\circ} \mathrm{C}$ or $-20^{\circ} \mathrm{C}$ until transformation.

MoClo reactions were transformed into High Efficiency Chemically Competent NEB10 $\beta$ cells as per manufacturer's protocol and plated onto selective LB agar plates. 
PCR ligation protocol. A PCR was set up using the Q5 High Fidelity DNA Polymerase (using manufacturer's protocol) to insert a promoter into vector backbone via overlapping primers. After confirmation of a single band of the correct size through gel electrophoresis, the PCR was cleaned up using Zymo's DNA Clean and Concentrate Kit. A Polynucleotide Kinase reaction was set up using $10 \mu \mathrm{l}$ of DNA according to manufacturer's protocol, and incubated for $30 \mathrm{~min}$ at $37^{\circ} \mathrm{C}$, followed by $65^{\circ} \mathrm{C}$ for $20 \mathrm{~min}$. T4 DNA ligase and additional buffer was added to the reaction and incubated for 2 hours at RT. This reaction was transformed into High Efficiency Chemically Competent NEB10 $\beta$ cells and colonies analyzed after overnight growth on selective agar plates.

Chemical transformation optimization assay. $V$. natriegens ATCC 14048 cells were recovered overnight in a $15 \mathrm{~mL}$ BD Falcon tube (Thermofisher Scientific ) from a $17 \%-80{ }^{\circ} \mathrm{C}$ glycerol stock. Cells were serially diluted across columns of a $96 \mathrm{v}$-bottom deep well microtiter plate, starting with an 8:1 dilution of OD 3.0 overnight culture in column A, a subsequent twofold dilution in column $\mathrm{B}$, a subsequent two-fold dilution in column $\mathrm{C}$, and so forth. The dilution media used was either a BHIv2 or Vmax Express Media, for the express purpose of determining optimal OD and osmolarity agent concentration to induce chemical competence. The inoculated microtiter plate was incubated at $37^{\circ} \mathrm{C}$ for 4 hours at $275 \mathrm{rpm}$ and placed in a shaking Biotek Synergy H1M plate reader to quantify OD and background fluorescence of each well. The microtiter plate was then spun down at 4,500 g for $10 \mathrm{~min}$ in a Beckman Coulter Allegra X-12R. All supernatant was decanted and pellets were resuspended in $180 \mu \mathrm{L}$ of $1 \mathrm{M}$ sorbitol and incubated for 1 hour, shaking at $275 \mathrm{rpm}$ at $37^{\circ} \mathrm{C} .1 \mu \mathrm{L}$ of $100 \mathrm{ng} / \mu \mathrm{L}$ of plasmid DNA (pWGEY1T) expressing RFP was mixed into each well using a Rainin LTS 12-channel electronic repeater pipette $(.1-10 \mu \mathrm{L})$. After adding DNA, cells in the microtiter plate was subjected to heatshock at $42{ }^{\circ} \mathrm{C}$, by submerging the plate up to half plate height, ensuring complete immersion of the bottom of the deep well plate. The plate was subsequently recovered overnight in either 1) BHIv2 media or 2) Vmax Express media at $37^{\circ} \mathrm{C}$, by adding $1 \mathrm{~mL}$ of media per well to the sorbitol, DNA, and cell mixture of each well. In the morning, $100 \mu \mathrm{L}$ of each well was transferred to $1 \mathrm{~mL}$ of Vmax Express Media with $25 \mu \mathrm{g} / \mathrm{mL}$ tetracycline and grown at $800 \mathrm{rpm}$ at $37^{\circ} \mathrm{C}$ for one day. For the plate reader assay, $100 \mu \mathrm{L}$ was transferred from each well into a clear-bottom round well microtiter plate. The clear-bottom microtiter plate was read in the Biotek Synergy H1M for $\mathrm{OD}_{600}$ and RFP fluorescence (excitation wavelength 580, emission wavelength $610 \mathrm{~nm}$ ).

In vivo cloning. As per Huang et $\mathrm{al}^{7}$ : A PCR was set up using the Q5 High Fidelity DNA Polymerase (using manufacturer's protocol) to insert a promoter into vector backbone via overlapping primers and run for 20 cycles. Less than $5 \mathrm{ng}$ of template was used. A second PCR was then set up similarly, with $0.5 \mu \mathrm{l}$ of a 1:1000 dilution of the first PCR as template. After confirmation of a single band of the correct size through gel electrophoresis, $5 \mu 1$ of the PCR was transformed into an aliquot of the NEB $10 \beta$ chemically competent cells, plated onto selective LB plate and incubated overnight at $37^{\circ} \mathrm{C}$.

Gibson assembly. NEB's Gibson Master Mix was used according to manufacturer's protocol. 
Microscopy. An upright Olympus BX53 fluorescent microscope was used for capturing images of fluorescent cells. For GFP, sfgfp, meSCFP3, and YFP, the 49002-BX3; ETEGFP/FITC/CY2 470/40X, BS495, 525/50M filter cube was used. For mcherry and RFP the 49008-BX3; ET-MCHERRY/TXRED 560/40X BS585, 630/75M filter cube was used. For eBFP2 the 49028-BX3; ET-DAPI 395/25X, BS425, 460/50M filter cube was used. Images were captured at $60 \mathrm{X}$ resolution.

Media for tyrosinase activity and melanin generation. Tyrosinase production and activity media contains the following: $1 \mathrm{X} \mathrm{M} 9$ salts, $2 \mathrm{mM} \mathrm{MgSO}_{4}, 0.1 \mathrm{mM} \mathrm{CaCl}_{2}, 10 \mu \mathrm{g} / \mathrm{ml}$ $\mathrm{CuSO}_{4}, 0.4 \mathrm{mg} / \mathrm{ml}$ L-tyrosine, $0.4 \%$ glycerol. Where the pJV-tyr plasmid was used, chloramphenicol was added to the media. Where $V$. natriegens was used, $300 \mathrm{mM} \mathrm{NaCl}$ was added to the media. IPTG at $100 \mu \mathrm{M}$ or arabinose at $0.2 \%$ were used for induction of the tyrosinase enzyme. Cells were inoculated at $2 \%$ and grown in $37^{\circ} \mathrm{C}$ overnight before pictures in Figure S3 were taken.

\section{SUPPLEMENTAL REFERENCES}

[1] Ohlendorf, R., Vidavski, R. R., Eldar, A., Moffat, K., and Moglich, A. (2012) From dusk till dawn: one-plasmid systems for light-regulated gene expression, Journal of Molecular Biology 416, 534542.

[2] Kushwaha, M., and Salis, H. M. (2015) A portable expression resource for engineering cross-species genetic circuits and pathways, Nature Communications 6, 7832.

[3] Riboli, B., Pedroni, P., Cuzzoni, A., Grandi, G., and de Ferra, F. (1991) Expression of Bordetella pertussis fimbrial (fim) genes in Bordetella bronchiseptica: fimX is expressed at a low level and vir-regulated, Microbial Pathogenesis 10, 393-403.

[4] Lou, C., Stanton, B., Chen, Y.-J., Munsky, B., and Voigt, C. A. (2012) Ribozyme-based insulator parts buffer synthetic circuits from genetic context, Nature Biotechnology 30, 1137-1142.

[5] Moore, S. J., Lai, H. E., Kelwick, R. J., Chee, S. M., Bell, D. J., Polizzi, K. M., and Freemont, P. S. (2016) EcoFlex: A multifunctional MoClo kit for E. coli synthetic biology, ACS Synthetic Biology 5, 1059-1069.

[6] Prindle, A., Samayoa, P., Razinkov, I., Danino, T., Tsimring, L. S., and Hasty, J. (2011) A sensing array of radically coupled genetic 'biopixels', Nature 481, 39-44.

[7] Huang, F., Spangler, J. R., and Huang, A. Y. (2017) In vivo cloning of up to $16 \mathrm{~kb}$ plasmids in E. coli is as simple as PCR, PloS One 12, e0183974. 